\title{
Effectiveness of Teaching Program on Awareness Regarding the Minor Discomfort Problems among Pregnant Women
}

\author{
${ }^{1}$ Hager Abdalalla Hashem; ${ }^{2}$ Ekbal Abdel Reheem Emam; ${ }^{3}$ Amany Hassan Abd Elrahim
}

(1) B.Sc. in Nursing, Faculty of Nursing -Minia University

(2) Professor of Maternal Health and Obstetric Nursing, Faculty of Nursing -Minia University

(3) Lecturer of Maternal Health and Obstetric Nursing, Faculty of Nursing -Minia University

\begin{abstract}
Background: Most of the pregnant women experienced minor discomforts in their normal pregnancies. The current study aimed to evaluate the effectiveness of planned teaching program on awareness regarding minor discomfort problems among primigravida women. Design: Quasi-experimental research design was utilized to achieve the aim. A convenient sample includes 66 primigravida women accordingly; this study was conducted in two maternal health care centers in Minia city. a structured interview questionnaire was developed. The data collection tool consisted of 3 tools; the first tool: demographic data of the primigravida women; the second tool: knowledge assessment tool (pre posttest education): and the third tool: practice assessment tool. Results: Most of the primigravida women had poor awareness about minor discomfort during pregnancy in the pre-teaching program which decreases to the minority after post teaching program with a highly statistically significant difference. Also, more than three-quarters of them had a poor level in total practice about minor discomforts in the pre-teaching program which decrease to the minority in the post-teaching program with a highly statistically significant difference. In addition, there was a fair positive association between the total knowledge score and the total practice score of primigravida women in the pre-teaching program. Conclusion: The study concluded that the nursing teaching program was effective in improving awareness of pregnant women regarding minor discomfort problems among primigravida women. Recommendation: The study recommended the integration of the designed nursing instructions for primigravida in maternal health care centers.
\end{abstract} Keywords: Awareness, Minor Discomfort Problems, Pregnant Women, Teaching Program

\section{Introduction}

Most pregnant women have experienced mild pain. Physiological, anatomical, endocrine/hormonal changes in their usual pregnancies that may result in these minor discomforts. Hormonal changes during pregnancy can damage the emotions of women, rendering them more susceptible to anxiety. The gestational phase is also a possible stressor for women with pre-existing psychological health issues that occur during or soon after pregnancy and a relatively high-risk phase for women (Ayoub \& Awed, 2018).

Pregnancy may be followed by radical changes in the female body, leading to several discomforts called "minor pregnancy disorders or ailments." Because of hormonal, accommodative, metabolic, and postural changes, these minor disorders-occur. Most of these conditions are not hazardous; they are just a natural part of pregnancy and can be handled at home. Nausea, vomiting, weakness, and frequency of micturition are typical diseases of pregnancy during the first trimester. Heart pain, constipation, vaginal discharge, and backache in the second trimester. Hemorrhoids, leg cramps, edema, and insomnia are present in the third trimester (Vincent, et al., 2015).

Minor discomforts linked to pregnancy can be controlled by proper description, simple treatments, and adjustment of lifestyle habits. Pregnant women should also have a basic awareness of common minor discomforts. During pregnancy, they should also know how to conquer these discomforts. To prevent the risks associated with their mild pregnancy distress and to preserve their state of health. Providing information on pregnancy pain physiology, avoidance, and self-care will help to alleviate such maternity care-related anxiety and fears is healthy pregnancy with a physically safe and emotionally rewarding result for mother, child, and family (Khalil \& Hamad, 2019).

The birth of a healthy baby is the primary aim of any pregnancy. Many pregnant women rely on nurses during their P a g e | 147 pregnancy to provide reliable information and compassionate guidance. To respond effectively, nurses need to consider not only the minor discomforts but also the practice of self-care to mitigate them. In offering anticipatory advice to promote women's accountability for self-care activities, nurses may play a significant and critical role in clarifying misconceptions and correcting any misinformation. It is necessary to educate the pregnant mother to recognize safety threats posed by her lifestyle, cultural, social, behavioral, condition and environment and to recommend ways to improve them to prevent negative effects from the government (Pereira, et al., 2020).

Also, nurses must be mindful of the types of activities related to health in which pregnant mothers may be involved. If the nurses are adequately informed about self-care procedures, adequate referrals may be made to help pregnant mothers improve their recovery, deal with symptoms and treatment-related adverse side effects, protect and encourage their health. Maternity nurses also play a vital role in improving the standard of maternal care, providing information and resources for pregnant mothers. At the same time, the nurse can provide evaluation, health education, therapy \& appropriate referral for health promotion \& psychosocial services (Homer, et al., 2019).

\section{Significance of the Study}

Amasha and Heeba (2013) evaluated Jordanian women's awareness of pregnancy normal and abnormal signs concluded that, lack of awareness about abnormal signs of pregnancy regarding pregnant women attending antenatal care. A recent study was done by AbdElhaliem, AbdElhady \& Mohamed, (2018) in an outpatient clinic affiliated with the obstetric department at Benha University reported that $45 \%$ of the studied sample had incorrect knowledge about minor discomfort and utilization measures to relieve those so, it is important to evaluate the effectiveness of planned teaching

Hager A., et al 
program on awareness regarding minor discomfort problems among primigravida women in Minia city.

\section{Aim of the study: \\ This study aimed to:}

Evaluate the effectiveness of planned teaching program on awareness regarding minor discomfort problems among primigravida women.

\section{Research Hypothesis:}

The utilization of teaching program will increase the awareness of primigravida women regarding minor discomfort.

\section{Subjects and Method \\ Research Design}

A quasi-experimental research design was utilized in the current study.

\section{Research Setting:}

This study was conducted in two maternal health care centers in Minia city (East, and West). This center was selected because has a high flow rate of pregnant women.

\section{Sampling}

A convenient sample includes 66 primigravida women accordingly; this study was conducted in two maternal health care centers in Minia city (East, and West). This center was selected because has a high flow rate of pregnant women.

\section{The sample size determined according to: \\ - $\quad \mathrm{N}=\mathrm{P} *(1-\mathrm{p}) *(\mathrm{Z} \alpha) / \mathrm{d}) 2$ \\ - $\mathrm{N}=(1.96) 2 *(.04 *(1-.04) * /(0.05) 2$}

\section{Description:}

- (n) refer to sample size

- (P) refer to the prevalence of primigravida had minor discomfort in the first three months at maternal health care centers in Minia city0.04.

- (d) Refer to tolerated error/margin of error $=0.05$; confidence interval $(\mathrm{CI})=95 \%$, the value for $(\mathrm{Z} \alpha)=$ 1.96 .

\section{Subjects}

\section{Inclusion criteria}

- Women during first trimester $\leq 5$ weeks of gestation.

- Healthy pregnant women

- $\quad$ Read and write women

\section{Tools for Data Collection}

Tools of data collection were developed by the researcher after an extensive review of the literature and similar studies conducted elsewhere. After that the developed questionnaire are revised by 5 panels of obstetrical and gynecological experts in nursing staffs, a structured interview questionnaire was developed. The data collection tool consisted of 3 tools:

The first tool: Demographic data such as age, residence, education level, occupation, and source of information.

The second tool: Knowledge assessment tool (pre posttest education):

It was developed by the researcher after revising relevant literature and it concerned with the women's
Knowledge about minor discomfort problems it includes: MCQ questions regarding (types of minor discomfort problems, causes, complications, and management). It was content 11 questions.

\section{Scoring System:}

The women's answers related to awareness were scores and calculated. each complete correct answer was given a score of two, the incomplete correct answer was given a score of one and the wrong answer a score of zero these scores converted into a percent score (poor knowledge scored $(<50 \%)$, average knowledge $(50 \%-<75 \%)$ and good knowledge scored $(75 \%$ or more).

The third tool: The practice assessment tool was used to assess the practice on the management of minor discomfort. It was developed by the researcher after revising relevant literature and it concerned with how the women's manage their minor discomfort during pregnancy which includes (nausea, vomiting, heartburn, fatigue, and constipation

\section{Scoring System:}

Application of exercise by pregnant women was classified as follows: Each correct practice was given a score of 'one' and wrong practice a score of 'zero' respectively for every step of exercises. Poor practice scored $(<50 \%)$; average practice $(50 \%-75 \%)$; the good practice was considered if the percent score was $(75 \%$ or more). the observational checklist was graded as done and not done for every step of the exercise.

\section{Validity and Reliability}

To establish validity, the questionnaire will be piloted on a panel of 5 experts of Obstetrics and Gynecological staff, and Nursing professors who reviewed the instruments for clarity, relevance, comprehensiveness, understanding, applicability, and easiness, and will use alpha Cronbach's way to check the stability of the internal consistency of the instrument.

\section{Administrative design}

An official written approval letter clarifying the purpose of the present study was obtained from the dean of the Faculty of Nursing, as well as the Director of Minia university hospital for maternity and child as approval for data collection to conduct this study also an oral informed consent was obtained from included women in the study. It included a full explanation of the purpose of the present study, procedure, and rights for privacy and confidentiality.

\section{Data Collection Procedure:}

\section{Assessment phase:}

During the assessment phase demographic data such as age, residence, education level, family income, and source of information about minor discomfort and Obstetric history which include: gestational age, type of minor discomfort, time of started and duration in addition to woman's awareness regarding minor discomfort were assessed.

\section{Implementation phase:}

First, the researcher has interviewed the women in the antenatal clinic and introduced myself, briefly explained the nature and the purpose of the study to women. They were informed that participation in this study is voluntary and they 
have the right to withdraw at any time. Oral approval of women to share in this study was achieved. After obtaining the acceptance from the women to participate in the current study, the researcher provided an overview and clarified the assessment tools questions to the woman. Then, the SelfAdministered Questionnaire was distributed to each woman to assess their awareness regarding minor discomfort (pre-test).

The questionnaire took about 30-35 minutes to be completed. After assessing the woman's awareness, the program was implemented. The session was conducted for one hour started from 10 a.m. to 11 a.m. Health education sessions were given to the women in the form of lectures and group discussions by using audio-visual aids, it emphasized improving women's awareness regarding minor discomfort. The lectures included information about minor discomfort. The researcher was discussed to the women how to manage their minor discomfort using a checklist. An additional 15 minutes was assigned at the end of the lecture for an open discussion with them about this topic. The booklet containing information about the type of minor discomfort and management will be distributed to women at the end of the session.

\section{Evaluation phase:}

For each woman two evaluations were being done, the first one at the beginning of the study as a baseline data (pre-test). The second evaluation was conducted after one month of the educational program to detect the level of women's awareness after health education regarding minor discomfort (posttest) for final evaluation.

\section{Supportive material (Health education guideline):}

It was designed to enhance women's awareness and their health status regarding antenatal exercise. It was designed by the researcher in the form of a handout (booklet) using simple Arabic language and different illustrative pictures to facilitate understanding its content.

\section{Operational design \\ Pilot Study:}

A pilot study was conducted on $10 \%$ of primigravida women at the previously mentioned setting to assess the current study tools for its clarity, validity, and time required to be applied. According to the results of the pilot, all required and necessary modifications were done and the women who were tested in the pilot study were included in the study sample.

\section{Ethical consideration:}

- The research proposal was approved by the ethical committee and the postgraduate committee in the faculty of nursing.

- Official permission was obtained from the dean of the Faculty of Nursing and requested from the Director of health affairs.

- Consent was obtained from primigravida women that are willing to participate in the study, after explaining the nature and purpose of the study.

- The study subject had the right to refuse to participate or withdraw from the study without any rationale at any time.

- Study subject privacy was considered during the collection of data

- Participants were assured that all their data are highly confidential.

\section{Statistical Design:}

The collected data were organized, categorized, and analyzed using the statistical package of social science (SPSS) IBM 25 and excel for figures. Data were presented using descriptive statistics in the form of frequencies and percentages for qualitative variables, and means and standard deviations for quantitative variables. The level of significance was be accepted at $\mathrm{P}<0.05$ and was be considered highly significant when P-value less than or equal to 0.01 .

\section{Results}

Table (1): Distribution of the primigravida women according to their demographic data (n=66).

\begin{tabular}{|c|c|c|}
\hline Demographic data & No. & $\%$ \\
\hline \multicolumn{3}{|l|}{ Age / years } \\
\hline $15-<20$ & 3 & 4.5 \\
\hline $20-<25$ & 21 & 31.8 \\
\hline $25-<30$ & 26 & 39.4 \\
\hline $30-<35$ & 12 & 18.2 \\
\hline$>35$ & 4 & 6.1 \\
\hline Mean \pm SD & \multicolumn{2}{|c|}{$28.4 \pm 4.30$ year } \\
\hline \multicolumn{3}{|l|}{ Residence } \\
\hline Rural & 37 & 56.1 \\
\hline Urban & 29 & 43.9 \\
\hline \multicolumn{3}{|l|}{ Education level } \\
\hline Read and write & 11 & 16.7 \\
\hline Primary & 7 & 10.6 \\
\hline Secondary & 34 & 51.5 \\
\hline University & 14 & 21.2 \\
\hline \multicolumn{3}{|l|}{ Occupation } \\
\hline Work & 11 & 16.7 \\
\hline Housewife & 55 & 83.3 \\
\hline
\end{tabular}

Table (1): shows that more than third (39.4\%) of the primigravida women aged between $25-30$ years with mean age $28.4 \pm$ 4.30 years, more than half $(56.1 \%)$ of them live in the rural area, about half $(51.5 \%)$ of them had secondary school and more than two-thirds $(83.3 \%)$ of them were housewives. 
Minia Scientific Nursing Journal (Print - ISSN 2537-012X) (Online - ISSN 2785-9797) Vol. (8) No. (1) December 2020

Table (2): Mean scores of the primigravida women awareness about minor discomforts problems in pre and post-teaching programs $(n=66)$.

\begin{tabular}{|c|c|c|c|c|}
\hline Knowledge & Pre & Post & t- test & P-value \\
\hline General knowledge & $3.1 \pm .9$ & $4.6 \pm .6$ & 11.157 & $.0001 * *$ \\
\hline Nausea and vomiting & $3.4 \pm .9$ & $7.5 \pm 1.4$ & 19.938 & $.0001 * *$ \\
\hline Heartburn & $2.3 \pm .7$ & $4.7 \pm 1.5$ & 11.605 & $.0001 * *$ \\
\hline Constipation & $3.2 \pm 1.0$ & $4.9 \pm .8$ & 11.451 & $.0001 * *$ \\
\hline Fatigue & $3.1 \pm 1.0$ & $4.9 \pm .9$ & 11.213 & $.0001 * *$ \\
\hline Ptyalism & $4.2 \pm 1.4$ & $7.6 \pm 1.5$ & 13.696 & $.0001 * *$ \\
\hline Hemorrhoid & $2.2 \pm .5$ & $4.1 \pm 1.4$ & 10.481 & $.0001 * *$ \\
\hline Varicose vein & $2.2 \pm .5$ & $4.4 \pm 1.2$ & 14.144 & $.0001 * *$ \\
\hline Shortness of breath and dyspnea & $2.3 \pm .6$ & $5.2 \pm .8$ & 23.625 & $.0001 * *$ \\
\hline Urinary Frequency and Urgency & $2.8 \pm .6$ & $5.1 \pm .9$ & 17.064 & $.0001 * *$ \\
\hline Total awareness about minor discomforts problems & $19.3 \pm 7.7$ & $52.7 \pm 8.3$ & 23.977 & $.0001 * *$ \\
\hline
\end{tabular}

** Highly statistically significant differences

Table (2): presents that there was an increase in mean scores of the primigravida women awareness post teaching program about all items of minor discomforts problems during pregnancy than a pre-teaching program with highly statistically significant differences.

Table (3): Mean scores of pre and post-self-care management about minor discomforts problems among the primigravida women $(n=66)$.

\begin{tabular}{|c|c|c|c|c|}
\hline Practices & Pre & Post & t-test & P-value \\
\hline Nausea and vomiting & $4.2 \pm 2.1$ & $8.9 \pm 2.5$ & 11.577 & $.0001^{* *}$ \\
\hline Heartburn & $4.9 \pm 2.0$ & $9.2 \pm 1.1$ & 15.131 & $.0001 * *$ \\
\hline Constipation & $2.8 \pm 1.6$ & $5.5 \pm 1.0$ & 11.033 & $.0001 * *$ \\
\hline Fatigue & $2.1 \pm 1.2$ & $4.3 \pm .8$ & 12.068 & $.0001 * *$ \\
\hline Ptylism & $1.0 \pm .9$ & $2.1 \pm .8$ & 6.837 & $.0001 * *$ \\
\hline Hemorrhoids & $1.7 \pm 1.3$ & $4.4 \pm 1.2$ & 12.557 & $.0001 * *$ \\
\hline Varicose vein & $.1 \pm .2$ & $.6 \pm .5$ & 8.361 & $.0001 * *$ \\
\hline Shortness of breath and dyspnea & $3.5 \pm 1.8$ & $5.6 \pm 1.2$ & 8.038 & $.0001 * *$ \\
\hline Urinary Frequency and Urgency & $1.9 \pm 1.1$ & $3.9 \pm 1.0$ & 10.804 & $.0001 * *$ \\
\hline Total practice & $22.1 \pm 9.5$ & $44.5 \pm 6.9$ & 15.429 & $.0001 * *$ \\
\hline
\end{tabular}

** Highly statistically significant differences

Table (3): indicates that there was an increase in mean scores of self-care management post teaching program about minor discomforts among the primigravida women than a pre-teaching program with highly statistically significant differences

\subsection{0\% Total Awareness level}

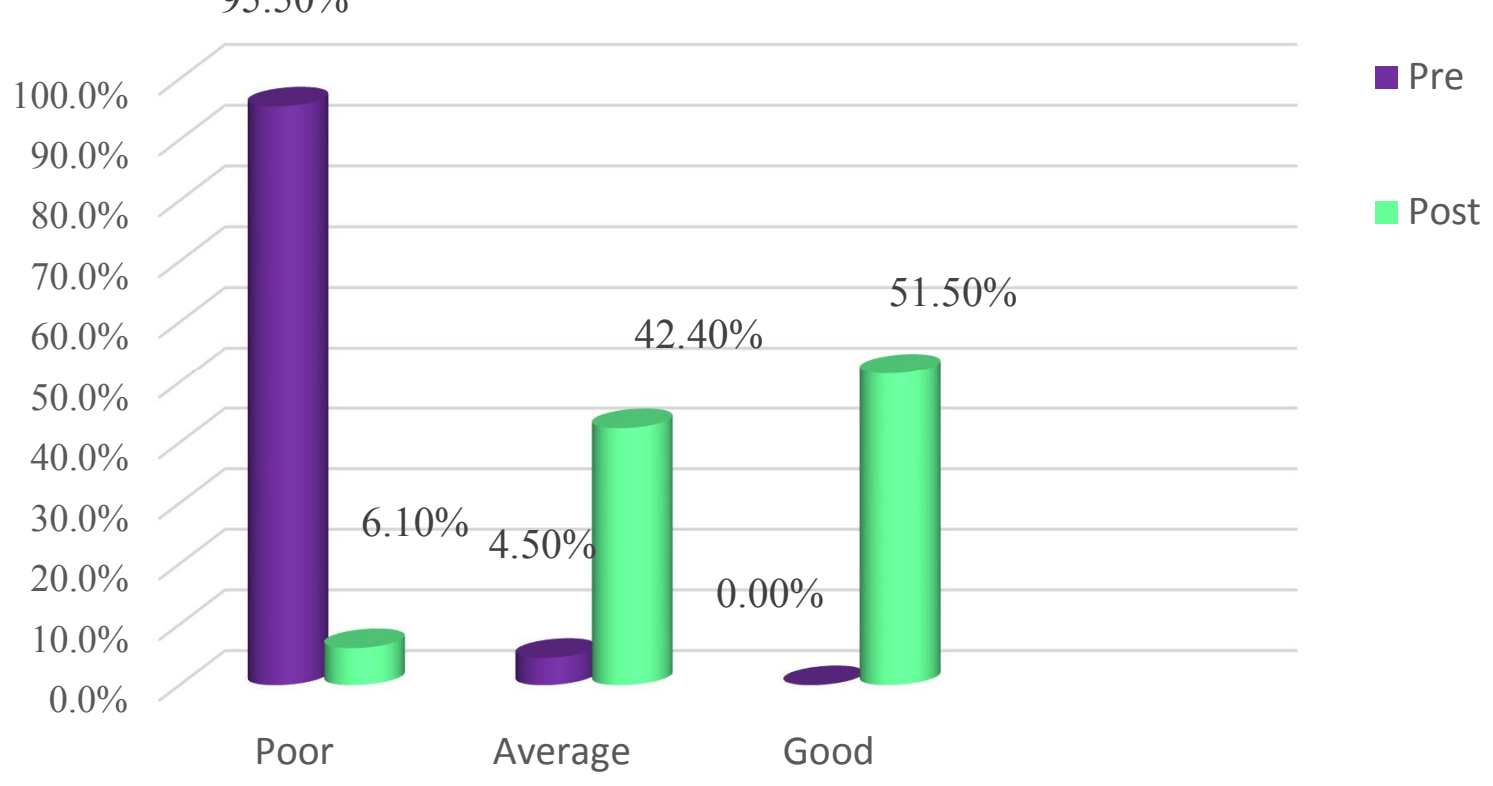

Figure (1): Comparison between pre \& post teaching program among the primigravida women regard their total awareness level about minor discomfort $(n=66)$

Figure (1): demonstrates that $95.5 \%$ of primigravida women had poor awareness level about minor discomfort problems during pregnancy pre-teaching program decrease to $6.1 \%$ of them post teaching program, $4.5 \%$ of them had average level preteaching program increased to $42.4 \%$ of them post teaching program and none of them had good level pre-teaching program increased to $51.5 \%$ of them post teaching program with a highly statistically significant difference with $\mathrm{P}$ value $<.0001$. 


\section{$77.30 \% \quad$ Total practice level}

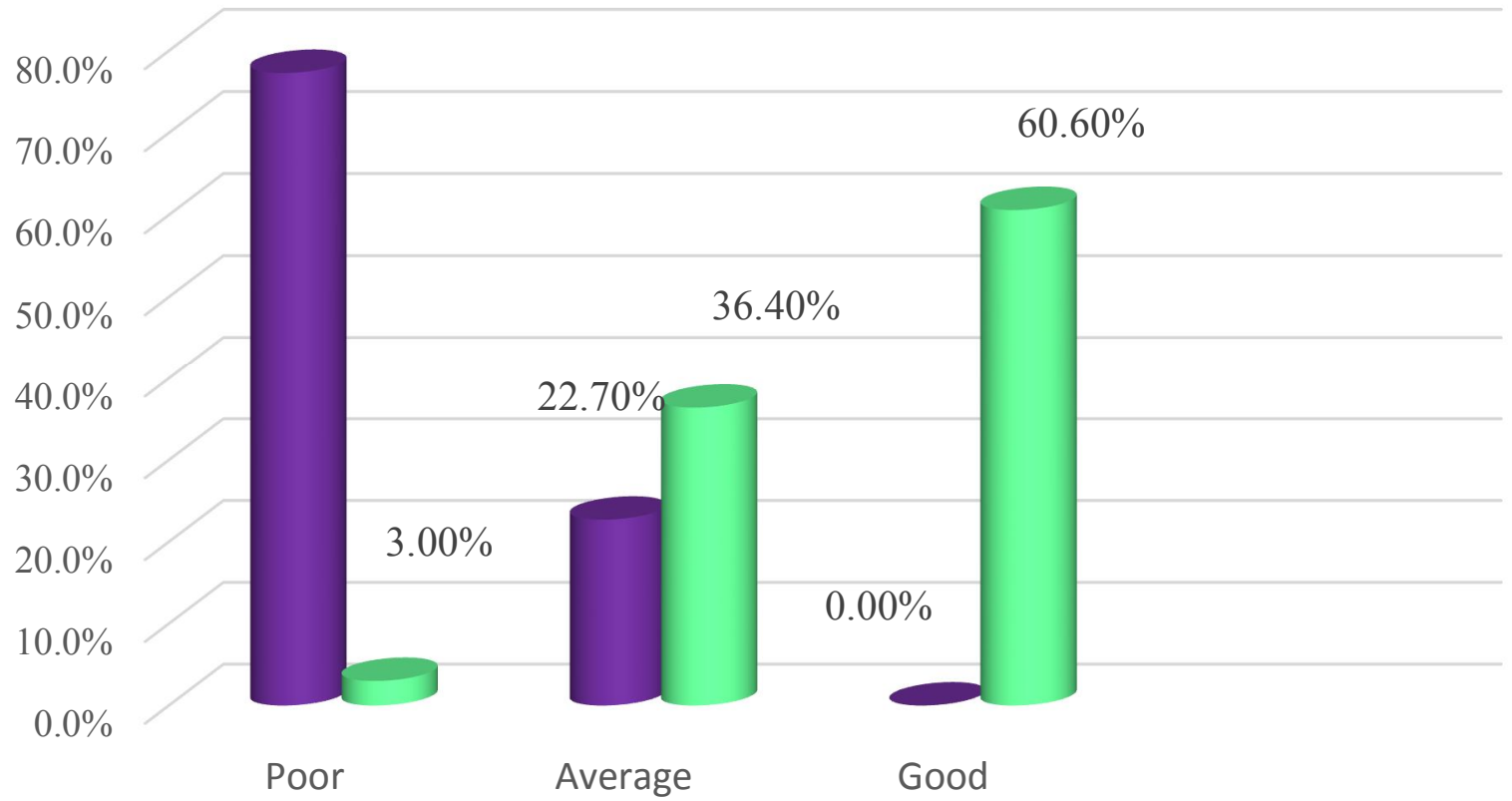

Pre Post

Figure (2): Comparison between pre \& post teaching program among the primigravida women regard total self-care practice level for management of minor discomforts problems $(n=66)$

Figure (2): demonstrates that $77.3 \%$ of primigravida women had a poor level in total practice about minor discomforts preteaching program decrease to $3.0 \%$ of them post teaching program, $22.7 \%$ of them had an average level in total practice pre-teaching program increased to $36.4 \%$ of them post teaching program and none of them had a good level in total practice pre-teaching program increased to $60.6 \%$ of them post teaching program with a highly statistically significant difference with $\mathrm{P}$ value $<.0001$.

Table (4): Relation between total knowledge level pre-teaching program of the primigravida women and their demographic characteristics $(n=66)$

\begin{tabular}{|c|c|c|c|c|c|c|}
\hline \multirow{3}{*}{ Demographic characteristics } & \multicolumn{4}{|c|}{ Total knowledge level (pre) } & \multicolumn{2}{|c|}{ Test of significance } \\
\hline & \multicolumn{2}{|c|}{ Poor $(n=63)$} & \multicolumn{2}{|c|}{ Average $(n=3)$} & \multirow[t]{2}{*}{$\mathbf{X}^{2}$} & \multirow[t]{2}{*}{ P-value } \\
\hline & No. & $\%$ & No. & $\%$ & & \\
\hline \multicolumn{7}{|l|}{ Age / years } \\
\hline $15-<20$ & 3 & 100.0 & 0 & .0 & \multirow{5}{*}{5.426} & \multirow{5}{*}{.246} \\
\hline $20-<25$ & 21 & 100.0 & 0 & .0 & & \\
\hline $25-<30$ & 25 & 96.2 & 1 & 3.8 & & \\
\hline $30-<35$ & 10 & 83.3 & 2 & 16.7 & & \\
\hline$>35$ & 4 & 100.0 & 0 & .0 & & \\
\hline \multicolumn{7}{|l|}{ Residence } \\
\hline Rural & 37 & 100.0 & 0 & .0 & \multirow[t]{2}{*}{4.010} & \multirow[t]{2}{*}{$.045 *$} \\
\hline Urban & 26 & 89.7 & 3 & 10.3 & & \\
\hline \multicolumn{7}{|l|}{ Education level } \\
\hline Read and write & 11 & 100.0 & 0 & .0 & \multirow{4}{*}{1.215} & \multirow{4}{*}{.749} \\
\hline Primary & 7 & 100.0 & 0 & .0 & & \\
\hline Secondary & 32 & 94.1 & 2 & 5.9 & & \\
\hline University & 13 & 92.9 & 1 & 7.1 & & \\
\hline \multicolumn{7}{|l|}{ Occupation } \\
\hline Work & 10 & 90.9 & 1 & 9.1 & \multirow[t]{2}{*}{.629} & \multirow[t]{2}{*}{.428} \\
\hline Housewife & 53 & 96.4 & 2 & 3.6 & & \\
\hline
\end{tabular}

\footnotetext{
$*=$ Statistical significance differences
}

Table (4): indicates that $10.3 \%$ of primigravida women live in urban areas had average knowledge levels with statistically significant difference which P-value $<.045$ but there was no statistically significant difference between age, teaching level, and their occupation and their total knowledge level pre-teaching program.

Table (5): Relation between total practice level pre-teaching program of the primigravida women and their demographic characteristics $(n=66)$.

\begin{tabular}{|c|c|c|c|c|c|c|}
\hline \multirow{3}{*}{ Demographic characteristics } & \multicolumn{4}{|c|}{ Total practice level (pre) } & \multicolumn{2}{|c|}{ Test of significance } \\
\hline & \multicolumn{2}{|c|}{ Poor $(n=51)$} & \multicolumn{2}{|c|}{ Average $(n=15)$} & \multirow[t]{2}{*}{$\mathbf{X}^{2}$} & \multirow[t]{2}{*}{ P-value } \\
\hline & No. & $\%$ & No. & $\%$ & & \\
\hline \multicolumn{7}{|l|}{ Age / years } \\
\hline
\end{tabular}


Minia Scientific Nursing Journal (Print - ISSN 2537-012X) (Online - ISSN 2785-9797) Vol. (8) No. (1) December 2020

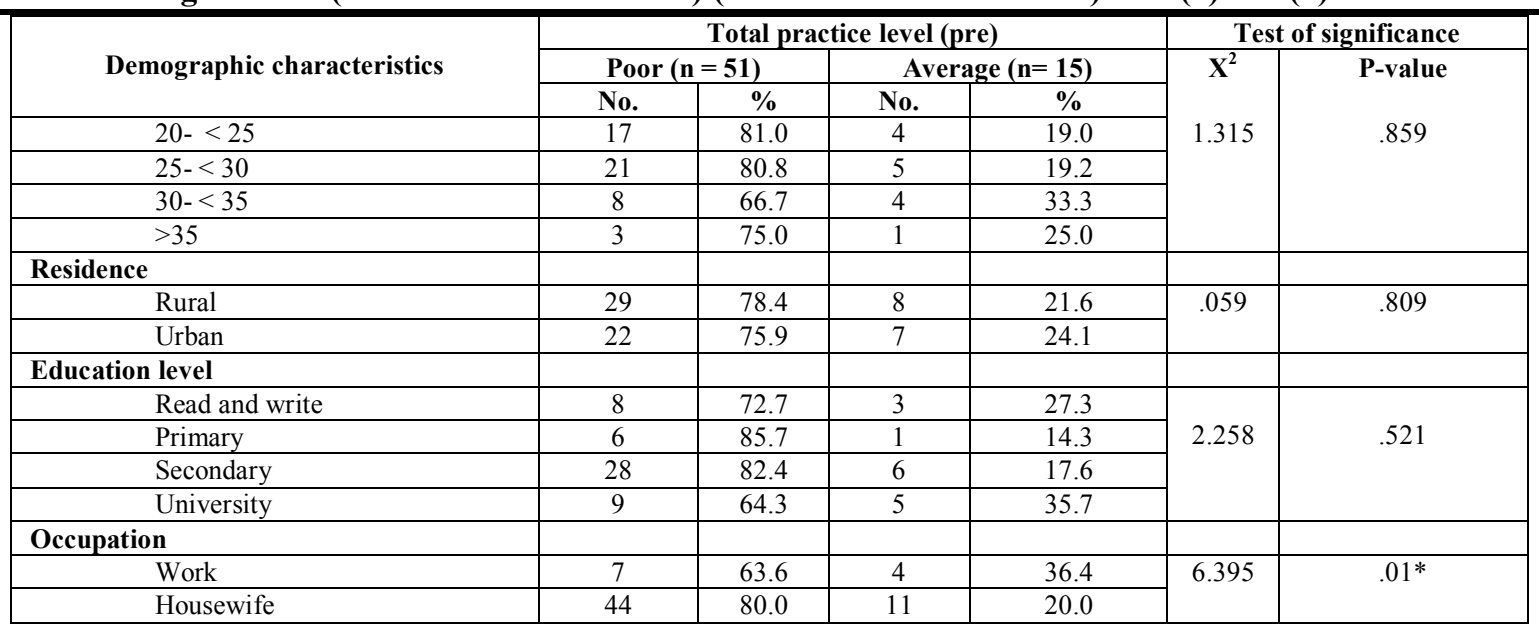

** Highly statistically significant differences

Table (5): presents that $36.4 \%$ of worked primigravida women had average practice levels than housewives' women with a statistically significant difference which P-value $<.01$ but there were no statistically significant differences between age, residence, teaching level of them and their total practice level pre-teaching program.

Table (6): Correlation matrix between total knowledge score and total self-reported practice score pre, and post-teaching program among the primigravida women

\begin{tabular}{|l|c|c|c|c|c|c|}
\hline \multirow{2}{*}{} & \multicolumn{2}{|c|}{$\begin{array}{c}\text { Total knowledge } \\
\text { score (pre) }\end{array}$} & $\begin{array}{c}\text { Total knowledge score } \\
\text { (post) }\end{array}$ & \multicolumn{2}{c|}{$\begin{array}{c}\text { Total practice } \\
\text { score (pre) }\end{array}$} \\
\cline { 2 - 7 } & $\mathrm{r}$ & $\mathrm{P}-$ value & $\mathrm{r}$ & $\mathrm{P}$-value & $\mathrm{r}$ & P-value \\
\hline Total knowledge score (pre) & & & & & & \\
\hline Total knowledge score (post) & .128 & .307 & & & & \\
\hline Total practice score (pre) & $\mathbf{. 2 5 6}$ & $\mathbf{. 0 3 8}$ & $\mathbf{. 2 4 2}$ & $\mathbf{. 0 5 0} *$ & & \\
\hline Total practice score (post) & .098 & .433 & $\mathbf{. 6 6 3}$ & $\mathbf{. 0 0 0 1 * *}$ & $\mathbf{. 2 7 7}$ & $\mathbf{. 0 2 4}^{*}$ \\
\hline
\end{tabular}

* Correlation is significant at the 0.05 level $* *$ Correlation is significant at the 0.01 level

Table (6): presents that there was a fair positive association between the total knowledge score of primigravida women preteaching program and their total practice scores pre-teaching program $(\mathrm{r}=.256 \& \mathrm{P}$ - value .038), there was a weak positive association between total knowledge score of primigravida women post teaching program and their total practice scores pre-teaching program $(\mathrm{r}=.242 \& \mathrm{P}$ - value .050), there was a strong positive association between total knowledge score of primigravida women post teaching program and their total practice scores post teaching program $(\mathrm{r}=.663 \& \mathrm{P}$ - value .0001$)$, and there was a fair positive association between total practice score of primigravida women pre-teaching program and their total practice scores post teaching program ( $\mathrm{r}=.277 \& \mathrm{P}$ - value .024$)$.

\section{Discussion}

The minor discomforts of pregnancy present difficulties for the health care provider as well as for the pregnant woman herself. Management of the various symptoms requires astute observations and the ability to individualize therapy (El-Sharkawy \& Araby, 2020).

Regarding the demographic data of primigravida women, the current study showed that more than one third $(39.4 \%)$ of the primigravida women aged between $25-30$ years with mean age $28.4 \pm 4.30$ years, more than half of them live in the rural area and had secondary school and $(83.3 \%)$ of them were housewives. This result comes in the line with Hassan et al., (2020) to evaluate the impact of a tailored educational program on primigravida anxiety and knowledge regarding minor discomforts in Upper Egypt and reported the mean age of the study sample was $(25.80 \pm 7.48)$, near to half $(38.0 \%)$ of them had secondary education, and $56.0 \%$ lives in a rural residence.

Regarding the mean scores of pre- and post-teaching program, the current study showed that there was an increase in mean scores of the primigravida women awareness post teaching program about all items of minor discomforts problems during pregnancy than a pre-teaching program with highly statistically significant differences. This result come in the line with (Hassan et al., 2020) who reported that the $P$ a g e | 152 majority of the primi mothers had medium knowledge and the most of them had good knowledge in pre-test. In post-test majority of primi mothers had reported excellent knowledge and remaining primi antenatal mothers were reported good knowledge and also report the pre-test mean was $8.12 \pm 2.96$ which was increased to $15.87 \pm 4.67$ in post-test.

Regarding the mean scores of pre- and post-self-care managements about minor discomforts problems among the primigravida women, the current study indicated that there was an increase in mean scores of self-care management post teaching program about minor discomforts among the primigravida women than a pre-teaching program with highly statistically significant differences.

This result supported by Thomas, (2017) show that the mean posttest practices score (55.05) is more than the pretest practice e scores (25.72). in order to find the difference in significance. Hence it can be inferred that there is difference in practices score after planned teaching program among sample Hence it can be inferred that there is a difference in practice score after planned teaching program among sample. Also, Ahmed, (2016) who stated that the level of woman's knowledge, health practices, and lifestyle increased after application of the intervention as compared with before and most women were satisfied after application of the intervention and there was a highly significant difference 
regarding knowledge, health practices, and lifestyle after application of the counseling intervention as compared with pre-application of the counseling intervention $(p<0.001)$.

Concerning the total awareness level about minor discomfort, the current study demonstrated that the majority of primigravida women had poor awareness level about minor discomfort problems during pregnancy pre-teaching program decrease to the minority of them post teaching program, and none of them had good level pre-teaching program increased to be more than half of them post teaching program with a highly statistically significant difference with $\mathrm{P}$ value $<.0001$.

This result comes in the line with Abd Elhaliem, AbdElhady, \& Mohamed, (2018) demonstrated that most of the studied women had poor knowledge pre-intervention regarding minor discomforts compared to none them postintervention also, Vincent, et al., (2015) conducted a descriptive study on knowledge of primi mothers on selfmanagement of minor discomfort of pregnancy intending to develop information' was carried out in Mangalore on 100 primigravida mothers by using a purposive sampling technique. The findings revealed that more than half $59 \%$ of the Primigravida mothers had poor knowledge, $29 \%$ had average knowledge, and $12 \%$ had good knowledge regarding minor discomforts of pregnancy and its self-management. This result might be due to the utilization of simple and clear language in the educational session and the appropriate teaching method and audiovisual aids.

Regarding total self-care practice level for management of minor discomforts problems, the current study demonstrated that the most of primigravida women had a poor level in total practice about minor discomforts pre-teaching program decrease to the minority of them post teaching program, more than one-fifth of them had an average level in total practice pre-teaching program increased to more than one-third of them post teaching program and none of them had a good level in total practice pre-teaching program increased to less than two-thirds of them post teaching program with a highly statistically significant difference with $\mathrm{P}$ value $<.0001$.

This result supported by Ahmed, (2016) who stated that the level of woman' health practices and life style increased after application of the intervention as compared with before and most of women were satisfied after application of the intervention and there was a high significant difference regarding knowledge, health practices and life style after application of the counseling intervention as compared with pre application of the counseling intervention $(p<0.001)$.

Regarding the relation between total knowledge level post teaching program of the primigravida women and their demographic characteristics, the current study presented that primigravida women aged between $20-$ 25 years had good knowledge post teaching program than other ages with statistically significance difference which Pvalue $<.005$ but there were no statistically significant differences between residence, teaching level, occupational of them and their total knowledge level post teaching program.

This result come consistent with Aldossary et al., (2018) who reported that there was significance differences between mothers knowledge score with their age. But this result differ with Hassan et al., (2020) who reported that a statistical significant relationship between the pregnant women's knowledge regarding minor disorders of pregnancy and their residences, occupation status $(\mathrm{P}<0.05)$.

Regarding the correlation matrix between total knowledge score and total self-reported practice score pre, and post-teaching program among the primigravida women, the current study presented that there was a fair positive association between the total knowledge score of primigravida women pre-teaching program and their total practice scores pre-teaching program $(\mathrm{r}=.256 \& \mathrm{P}$ - value .038$)$, there was a weak positive association between total knowledge score of primigravida women post teaching program and their total practice scores pre-teaching program $(\mathrm{r}=.242 \& \mathrm{P}$ - value $.050)$, there was a strong positive association between total knowledge score of primigravida women post teaching program and their total practice scores post teaching program $(\mathrm{r}=.663 \& \mathrm{P}-$ value .0001$)$, and there was a fair positive association between total practice score of primigravida women pre-teaching program and their total practice scores post teaching program $(\mathrm{r}=.277 \& \mathrm{P}$ - value .024$)$.

These results come in accordance with El-Sharkawy \& Araby, (2020) who studied "effectiveness of selfinstructional module on knowledge and remedial practices regarding selected minor ailments among primigravida" and reported that there was a non-significant positive correlation between total knowledge and total healthy practices regarding minor ailments at the pre-intervention phase $(\mathrm{P}>0.05)$. While there was a highly positive statistical correlation between total knowledge and total healthy practices regarding minor ailments at the post-intervention phase $(\mathrm{P} \leq 0.001)$.

\section{Conclusion} concluded that:

Based on the results of the present study, it can be

The study concluded that most of primigravida women had poor awareness level pre-teaching program decrease to the minority of them post teaching program, and none of them had good level pre-teaching program increased to half of them post teaching program, and more than threequarters of them had a poor level in total practice about minor discomforts pre-teaching program decrease to the minority of them post teaching program, and none of them had a good level in total practice pre-teaching program increased to near to two-third of them post teaching program with a highly statistically significant difference with $\mathrm{P}$ value $<.0001$.

\section{Recommendations}

Based on the results of the present study and research questions the following recommendations are suggested:

Counseling and nursing intervention for newly pregnant women about:

a) Most common minor discomfort during pregnancy.

b) Providing posters, booklets, and leaflets for newly pregnant women, which describe care.

c) Periodic antenatal care for pregnant women.

d) Providing practical guidance on every health issue regarding minor discomfort.

\section{References}

(1) AbdElhaliem, S., AbdElhady, R., \& Mohamed, A. (2018) Utilization of Self-Care Practice Guideline on Relieving Mino Discomfort (Ailments) Among New Pregnant Woman. IOSR Journal of Nursing and Health Science, 7(1), 07-15.

(2) Ahmed, A. (2016). Effect of Counseling Intervention on Women's Knowledge, Practices and Lifestyle of Fetal Well-being among Primigravidae. International Journal of Nursing Science, 6(4), 8793.

(3) Aldossary, A. D., Al Shamandy, S. A., \& Haitham, A. A. (2018). A cross sectional study about knowledge and practice of primigravida women: minor and common pregnancy discomforts. J Nurs Health Sci, 4(1), 32-45. 
(4) Amasha H., and Heeba M. (2013). Maternal Awareness of Pregnancy Normal and Abnormal Signs: An Exploratory Descriptive Study. IOSR Journal of Nursing and Health Science. Volume 2, Issue 5, PP 39-45.

(5) Ayoub, G., \& Awed, H. (2018). Comparative Study between Primigravida and Multigravida Regarding Women's Self-Care Practices for Management of Selected Minor Discomforts. Madridge J Case Rep Stud, 2(1), 1000111.

(6) El-Sharkawy, A. T., \& Araby, O. A. (2020). Effectiveness of Selfinstructional Module on Knowledge and Remedial Practices Regarding Selected Minor Ailments Among Primigravida. Evidence-Based Nursing Research, 2(2), 17-17.

(7) Hassan, H. E., Ahmed, W. F. M., \& Mahmoud, A. A. (2020). Impact of Tailored Educational Program on Primigravida Anxiety and Knowledge Regarding Minor Discomforts in Upper Egypt. International Journal of Studies in Nursing, 5(1), 1.

(8) Homer, C., Brodie, P., Sandall, J., \& Leap, N. (2019). Midwifery continuity of care: a practical guide: Elsevier Health Sciences.
(9) Khalil, H. M., \& Hamad, K. J. (2019). Knowledge of Minor Discomforts during Pregnancy among Pregnant Women Attending Maternal and Pediatric Hospital in Soran City. Polytechnic Journal, 9(2), 20-24

(10) Pereira, E., Portela, F., \& Abelha, A. (2020). A clinical recommendation system to maternity care Innovations in Global Maternal Health: Improving Prenatal and Postnatal Care Practices (pp. 1-20): IGI Global.

(11) Thomas, A. M. (2017). Effect of Planned Teaching Programme on Knowledge and Practices in Relation to Prevention of Complications among selected High Risk Antenatal Mothers in a Selected Hospital. Asian Journal of Nursing Education and Research, 7(3), 308-320.

(12) Vincent, S., Nayak, S., \& Paul, S. (2015). A study on knowledge of primi mothers on self management of minor discomforts of pregnancy. Nitte University Journal of Health Science, 5(2), 12 